\title{
A Simple Model to Estimate the Optimal Doping of p - Type Oxide Superconductors
}

\author{
Adir Moysés Luiz* \\ Centro de Tecnologia, Instituto de Física - UFRJ, \\ Bloco A, Sala A-319, 21941-972 Rio de Janeiro - RJ, Brazil
}

Received: October 25, 2008; Received December 11, 2008

\begin{abstract}
Oxygen doping of superconductors is discussed. Doping high- $T_{c}$ superconductors with oxygen seems to be more efficient than other doping procedures. Using the assumption of double valence fluctuations, we present a simple model to estimate the optimal doping of p-type oxide superconductors. The experimental values of oxygen content for optimal doping of the most important p-type oxide superconductors can be accounted for adequately using this simple model. We expect that our simple model will encourage further experimental and theoretical researches in superconducting materials.
\end{abstract}

Keywords: high-T $T_{c}$ superconductors, double valence fluctuations, valence skip, optimal doping

\section{Introduction}

Oxide superconductors have received enormous attention since the discovery of high- $\mathrm{T}_{c}$ oxide superconductors containing copper ${ }^{1}$. Recently, the synthesis of a high- $T_{c}$ superconductor without copper ${ }^{2}$, has opened a new discussion about the microscopic mechanisms responsible for superconductivity in high- $\mathrm{T}_{c}$ superconductors. In this work we denote by y an appropriate atomic fraction and by $\mathrm{T}_{c}$ the critical temperature of the superconductor. For a discussion of the historical development of the researches on oxide superconductors, see Cava ${ }^{3}$. In Table 1 we list in chronological order the most important discoveries of oxide superconductors.

The doping procedures used for the synthesis of cuprate superconductors have been described in a review article ${ }^{4}$. The first high- $\mathrm{T}_{c}$ oxide superconductor was the famous copper oxide ${ }^{1} \mathrm{La}_{2-\mathrm{y}} \mathrm{Ba}_{\mathrm{y}} \mathrm{CuO}_{4}$; this superconductor is synthesized by doping the parent material $\mathrm{La}_{2} \mathrm{CuO}_{4}$ with $\mathrm{Ba}$ atoms. Soon after this discovery, it was realized that doping the parent material $\mathrm{La}_{2} \mathrm{CuO}_{4}$ with oxygen, without the introduction of any $\mathrm{Ba}$ atomic fraction $\mathrm{y}$, it is also possible to synthesize the superconductor ${ }^{5} \mathrm{La}_{2} \mathrm{CuO}_{4+\mathrm{y}}$. In this case, we conclude that the introduction of oxygen is responsible for the doping mechanism of the parent material $\mathrm{La}_{2} \mathrm{CuO}_{4}$. In the superconductor $\mathrm{GdFeAsO}_{1-\mathrm{y}}$, a high- $\mathrm{T}_{\mathrm{c}}$ superconductor with oxygen-deficiency, it has been shown ${ }^{2}$ that oxygen doping is a good and reliable procedure for the synthesis of a new family of iron-based high-T superconductors.

It is well known that for p-type oxide superconductors the optimal oxygen doping of high- $\mathrm{T}_{\mathrm{c}}$ oxide superconductors corresponds to a certain critical hole content. An under-doped superconductor is synthesized when the hole content is less than this critical value and an over-doped superconductor is synthesized when the hole content is greater than this critical value. The prediction of the optimal doping is an unresolved issue. In this work we propose a simple model to estimate the optimal doping of p-type oxide superconductors.

\section{Double Valence Fluctuations and Valence Skip}

According to a number of tables in Lee ${ }^{14}$ we present in Table 2 the electron configurations and the oxidation states of some metals used in the synthesis of the oxide superconductors listed in Table 1. Examining Tables 1 and 2, we notice that: 1) In the superconductor $\mathrm{K}_{\mathrm{y}} \mathrm{WO}_{3}$, the metal $\mathrm{W}$ may have the oxidation states $\mathrm{W}(+\mathrm{IV})$ and $\mathrm{W}$
(+VI); 2) In $\mathrm{LiTi}_{2+\mathrm{y}} \mathrm{O}_{4}$ the metal $\mathrm{Ti}$ may have the oxidation states: $\mathrm{Ti}(+\mathrm{II})$ and $\mathrm{Ti}(+\mathrm{IV}) ; 3)$ In the superconductor $\mathrm{BaPb}_{1-\mathrm{y}} \mathrm{Bi}_{\mathrm{y}} \mathrm{O}_{3}$; the metal $\mathrm{Pb}$ may have the oxidation states: $\mathrm{Pb}(+\mathrm{II})$ and $\mathrm{Pb}(+\mathrm{IV})$ and $\mathrm{Bi}$ may have the oxidation states $\mathrm{Bi}(+\mathrm{III})$ and $\mathrm{Bi}(+\mathrm{V})$; 4) In all cuprate superconductors listed in Table 1, Cu may have the unstable oxidation states $\mathrm{Cu}(+\mathrm{I})$ and $\mathrm{Cu}(+\mathrm{III})$; and 5) In the new superconductor containing iron $^{2}$, Fe may have the oxidation states Fe $(+\mathrm{II})$ and $\mathrm{Fe}(+\mathrm{IV})$ and As may have the oxidation states As (+III) and As (+V).

According to a number of authors ${ }^{15-18}$, the existence of double valence fluctuations in oxide superconductors is very likely. Ganguly and Hegde ${ }^{15}$ argued that: "Apparently, the presence of double valence fluctuations is a necessary, but not sufficient, criterion for superconductivity." Possible microscopic mechanisms for double valence fluctuations are hopping mechanisms ${ }^{19,20}$, tunneling mechanisms ${ }^{21}$, or bipolaronic mechanisms ${ }^{22}$.

Jongh $^{23}$ claims that oxide materials may become superconductors when a parent material is doped by the traditional doping mechanism with cation (or anion) substitution or by a doping mechanism due to oxygen non - stoichiometry. If a certain oxide contains a metal with mixed oxidation numbers, by increasing (or decreasing) the oxygen content, the metal may be oxidized (or reduced) in order to maintain charge neutrality. Thus, the synthesis of p-type superconductors may be obtained by doping the parent materials with an excess of oxygen atoms and the synthesis of n-type superconductors may be obtained by doping the parent materials with a deficiency of oxygen atoms.

Our basic assumption is that the existence of double valence fluctuations involving paired electrons (or paired holes) may be a key to the study of the microscopic mechanisms in oxide superconductors. Let us consider the case of an oxide superconductor containing $\mathrm{Bi}$ without copper (see Table 1). In this case, $\mathrm{Bi}(+\mathrm{III})$ and $\mathrm{Bi}(+\mathrm{V})$ are stable oxidation states. This element belongs to the class of elements with valence skip, that is, the valence $\mathrm{Bi}(+\mathrm{IV})$ is not present in the compounds containing $\mathrm{Bi}$; only mixtures of the species $\mathrm{Bi}(+\mathrm{III})$ and $\mathrm{Bi}(+\mathrm{V})$ are possible. The same phenomenon of valence skip also occurs in the case of $\mathrm{Pb}$ compounds; only mixtures of $\mathrm{Pb}(+\mathrm{II})$ and $\mathrm{Pb}(+\mathrm{IV})$ are possible. About fifteen elements in periodic table skip certain valence in all the components they form. Varma ${ }^{18}$ argued that the elements with valence skip may be used in the synthesis of superconductors. 
Table 1. Most important oxide superconductors in chronological order.

\begin{tabular}{lccc}
\multicolumn{1}{c}{ Superconductor } & Year & $\mathrm{T}_{\mathrm{C}}(\mathrm{K})$ & Reference \\
\hline $\mathrm{K}_{\mathrm{y}} \mathrm{WO}_{3}$ & 1967 & 6.0 & 7 \\
$\mathrm{LiTi}_{2+\mathrm{y}} \mathrm{O}_{4}$ & 1973 & 1.2 & 8 \\
$\mathrm{BaPb}_{1-\mathrm{y}} \mathrm{Bi}_{\mathrm{y}} \mathrm{O}_{3}$ & 1975 & 13 & 9 \\
$\mathrm{La}_{2-\mathrm{y}} \mathrm{Ba}_{\mathrm{y}} \mathrm{CuO}_{4}$ & 1986 & 30 & 1 \\
$\mathrm{YBa}_{2} \mathrm{Cu}_{3} \mathrm{O}_{7-\mathrm{y}}$ & 1987 & 90 & 6 \\
$\mathrm{Ba}_{1-\mathrm{y}} \mathrm{K}_{\mathrm{y}} \mathrm{BiO}_{3}$ & 1988 & 20 & 10 \\
$\mathrm{BiSrCaCu}_{2} \mathrm{O}_{6+\mathrm{y}}$ & 1988 & 105 & 11 \\
$\mathrm{TlBa}_{2} \mathrm{Ca}_{2} \mathrm{Cu}_{3} \mathrm{O}_{9+\mathrm{y}}$ & 1989 & 110 & 12 \\
$\mathrm{HgBa}_{2} \mathrm{CaCu}_{2} \mathrm{O}_{6+\mathrm{y}}$ & 1993 & 120 & 13 \\
$\mathrm{GdFeAsO}_{1-\mathrm{y}}$ & 2008 & 53.5 & 2 \\
\hline
\end{tabular}

Table 2. Electron configurations and oxidation states of some metals. The symbol $[\mathrm{Xe}]$ means the electron configuration of $\mathrm{Xe}$ and $[\mathrm{Ar}]$ means the electron configuration of Ar.

\begin{tabular}{cll}
\hline Metal & Electron configurations & Oxidation states \\
\hline $\mathrm{As}$ & {$[\mathrm{Ar}] 3 \mathrm{~d}^{10} 4 \mathrm{~s}^{2} 4 \mathrm{p}^{3}$} & $+\mathrm{III},+\mathrm{V}$ \\
$\mathrm{Bi}$ & {$[\mathrm{Xe}] 4 \mathrm{f}^{14} 5 \mathrm{~d}^{10} 6 \mathrm{~s}^{2} 6 \mathrm{p}^{3}$} & $+\mathrm{III},+\mathrm{V}$ \\
$\mathrm{Cu}$ & {$[\mathrm{Ar}] 3 \mathrm{~d}^{10} 4 \mathrm{~s}^{1}$} & $+\mathrm{I},+\mathrm{II},+\mathrm{III}$ \\
$\mathrm{Fe}$ & {$[\mathrm{Ar}] 3 \mathrm{~d}^{6} 4 \mathrm{~s}^{2}$} & $+\mathrm{II},+\mathrm{III},+\mathrm{IV},+\mathrm{V}$ \\
$\mathrm{Pb}$ & {$[\mathrm{Xe}] 4 \mathrm{f}^{14} 5 \mathrm{~d}^{10} 6 \mathrm{~s}^{2} 6 \mathrm{p}^{2}$} & $+\mathrm{II},+\mathrm{IV}$ \\
$\mathrm{Ti}$ & {$[\mathrm{Ar}] 3 \mathrm{~d}^{2} 4 \mathrm{~s}^{2}$} & $+\mathrm{II},+\mathrm{III},+\mathrm{IV}$ \\
$\mathrm{Tl}$ & {$[\mathrm{Xe}] 4 \mathrm{f}^{14} 5 \mathrm{~d}^{10} 6 \mathrm{~s}^{2} 6 \mathrm{p}^{1}$} & $+\mathrm{I},+\mathrm{III}$ \\
$\mathrm{W}$ & {$[\mathrm{Xe}] 4 \mathrm{f}^{14} 5 \mathrm{~d}^{4} 6 \mathrm{~s}^{2}$} & $+\mathrm{IV},+\mathrm{V},+\mathrm{VI}$ \\
\hline
\end{tabular}

\section{Optimal Doping of $\mathbf{p}$ - Type Oxide Superconductors}

Let us now consider cuprate superconductors without Bi. In Table 2 we note that copper is not an element with valence skip. But, if one wants to apply the assumption of double valence fluctuations to a cuprate superconductor, it is necessary to assume the existence of the states $\mathrm{Cu}(+\mathrm{I})$ and $\mathrm{Cu}(+\mathrm{III})$. However, since $\mathrm{Cu}(+\mathrm{I})$ and $\mathrm{Cu}$ $(+\mathrm{III})$ are not stable oxidation states, it is very difficult to perform reliable experiments to verify this hypothesis. Nevertheless, this assumption is supported by the possible occurrence of the following disproportionation reaction: $2 \mathrm{Cu}(+\mathrm{II}) \rightarrow \mathrm{Cu}(+\mathrm{I})+\mathrm{Cu}(+\mathrm{III})$. which has been suggested by Raveau et al. ${ }^{24}$ to explain the existence of the state $\mathrm{Cu}(+\mathrm{III})$.

What should be the optimal chemical doping of cuprate superconductors in order to obtain the maximum value of $\mathrm{T}_{c}$ ? To answer this question we present a simple model based on the conjecture of double valence fluctuations.

According to Zhang and Sato ${ }^{25}$ there is a universal relationship between hole content and $\mathrm{T}_{\mathrm{c} \text {. }}$ Examining the figure that shows this universal relationship ${ }^{25}$, we observe that the optimal doping corresponds to a certain critical value of hole concentration that gives the maximum $\mathrm{T}_{c}$. In the case of p-type cuprate superconductors this critical value corresponds to a situation of a critical oxygen content. Considering disproportionation reactions ${ }^{24}$, we may suppose initially an equal probability of occurrence of the ions $\mathrm{Cu}(+\mathrm{I}), \mathrm{Cu}(+\mathrm{II})$ and $\mathrm{Cu}$ (+III). Under this hypothesis, the initial concentrations of the copper ions are: $(1 / 3) \mathrm{Cu}(+\mathrm{I}),(1 / 3) \mathrm{Cu}(+\mathrm{II})$ and $(1 / 3) \mathrm{Cu}(+\mathrm{III})$. By diffusion, it is possible to introduce in the material an excess of oxygen atoms. We know that oxygen excess may produce an oxidation reaction, converting the species $\mathrm{Cu}(+\mathrm{II})$ into the ion $\mathrm{Cu}(+\mathrm{III})$. Let us suppose a complete oxidation with conversion of all the initial (1/3) $\mathrm{Cu}(+\mathrm{II})$ ions into $(1 / 3) \mathrm{Cu}(+\mathrm{III})$ ions. Then, the initial concentration of $(1 / 3)$ $\mathrm{Cu}(+\mathrm{III})$ ions is enhanced by the fraction $(1 / 3) \mathrm{Cu}(+\mathrm{III})$. Thus, the final concentration of $\mathrm{Cu}(+\mathrm{III})$ ions is given by $(1 / 3)+(1 / 3)=(2 / 3)$. Therefore, applying this assumption, we conclude that for optimal doping of p-type cuprate superconductors, the final concentrations of the copper ions are given by the following proportionalities: (1/3) $\mathrm{Cu}(+\mathrm{I})$ ions and $(2 / 3) \mathrm{Cu}(+\mathrm{III})$ ions.

\section{Results and Discussion}

We apply the simple hypothesis described above to estimate the optimal doping of the famous p-type cuprate superconductor $\mathrm{YBa}_{2} \mathrm{Cu}_{3} \mathrm{O}_{y}$, where $\mathrm{y}$ is the oxygen content to be calculated. Using the relative values: $(1 / 3)$ for $\mathrm{Cu}(+\mathrm{I})$ and $(2 / 3)$ for $\mathrm{Cu}(+\mathrm{III})$, we may write the formula unit: $\mathrm{YBa}_{2} \mathrm{Cu}_{1}(+\mathrm{I}) \mathrm{Cu}_{2}(+\mathrm{III}) \mathrm{O}_{\mathrm{y}}$. Considering the oxidation states $\left.\mathrm{Y}(+\mathrm{III}), \mathrm{Ba}^{2}+\mathrm{II}\right)$ and $\mathrm{O}(-\mathrm{II})$ and using the charge neutrality condition, gives:

$$
3+(2 \times 2)+(1 \times 1)+(2 \times 3)-2 y=0
$$

From Equation (1) we obtain: $y=7.0$. This result is in good agreement with the experimental result $(y=6.9)$ reported in the literature ${ }^{26}$. Using the model described in the previous calculation, we may estimate the necessary oxygen content to obtain the optimal doping of a great number of p-type cuprate superconductors. It is important to note that the experimental determination of the oxygen content is a difficult task. Therefore, we have selected a number of typical works which we believe to be reliable. In Table 3 we compare the predictions based on our simple model with the oxygen content obtained in these typical works. In our model, we have used for the copper ions the following relative values: $(1 / 3)$ for $\mathrm{Cu}(+\mathrm{I})$ ions and $(2 / 3)$ for $\mathrm{Cu}(+\mathrm{III})$ ions. For the other elements in Table 3 we have considered the following stable oxidation states: La (+III), Y (+III), $\mathrm{Ba}(+\mathrm{II}), \mathrm{Sr}(+\mathrm{II}), \mathrm{Bi}(+\mathrm{III}), \mathrm{Ca}(+\mathrm{II}), \mathrm{Tl}(+\mathrm{III}), \mathrm{Hg}(+\mathrm{II})$ and $\mathrm{O}(-\mathrm{II})$. We verify that the results predicted by the simple model proposed here are in good agreement with the experimental results listed in Table 3 .

The simple model suggested in this work has been applied only to the calculation of the optimal doping of superconductors doped with oxygen. To apply this model in the case of simultaneous doping with oxygen and other elements, such as in $\mathrm{Ba}_{\mathrm{x}} \mathrm{La}_{2-\mathrm{x}} \mathrm{CuO}_{4+\mathrm{y}}$ it is necessary to know the atomic fractions $\mathrm{x}$ and $\mathrm{y}$. In the case of simultaneous doping with oxygen and other elements we have not found in the literature simultaneous measurements of the variables $\mathrm{x}$ and $y$ and thus we have not compared the predictions of this simple model in this case.

Our model may be extended to estimate the optimal doping of oxide superconductors that do not contain $\mathrm{Cu}$. For example, consider the superconductor ${ }^{31} \mathrm{Ba}_{0.6} \mathrm{~K}_{0.4} \mathrm{BiO}_{3}$ with $\mathrm{T}_{\mathrm{c}}$ approximately equal to $30 \mathrm{~K}$. We shall suppose for the $\mathrm{Bi}$ ions the same proportionality assumed in the model just suggested for the cuprate superconductors, that is, for optimal doping, we assume that the relative concentrations should be given by: $(1 / 3) \mathrm{Bi}(+\mathrm{III})$ and $(2 / 3) \mathrm{Bi}(+\mathrm{V})$. Considering the oxidation states $\mathrm{Ba}(+\mathrm{II})$ and $\mathrm{K}(+\mathrm{I})$ and using the charge neutrality condition, we have:

$$
1.2+0.4+(1 / 3)(3)+(2 / 3)(5)-2 y=0
$$


Table 3. Optimal doping of p-type oxide superconductors containing copper.

\begin{tabular}{lcccc}
\hline Superconductor & $\mathrm{T}_{\mathrm{C}}(\mathrm{K})$ & $\begin{array}{c}\text { Oxygen } \\
\text { content } \\
\text { (Predicted) }\end{array}$ & $\begin{array}{c}\text { Oxygen } \\
\text { content } \\
\text { (Experimental) }\end{array}$ & Reference \\
\hline $\mathrm{La}_{2} \mathrm{CuO}_{\mathrm{y}}$ & 30 & $\mathrm{y}=4.2$ & $\mathrm{y}=4.1$ & 5 \\
$\mathrm{YBa}_{2} \mathrm{Cu}_{3} \mathrm{O}_{\mathrm{y}}$ & 90 & $\mathrm{y}=7.0$ & $\mathrm{y}=6.9$ & 26 \\
$\mathrm{YBa}_{2} \mathrm{Cu}_{4} \mathrm{O}_{\mathrm{y}}$ & 80 & $\mathrm{y}=8.2$ & $\mathrm{y}=8.0$ & 4 \\
$\mathrm{Sr}_{2} \mathrm{CuO}_{\mathrm{y}}$ & 70 & $\mathrm{y}=3.17$ & $\mathrm{y}=3.16$ & 27 \\
$\mathrm{Bi}_{2} \mathrm{CaSr}_{2} \mathrm{Cu}_{2} \mathrm{O}_{\mathrm{y}}$ & 85 & $\mathrm{y}=8.3$ & $\mathrm{y}=8.3$ & 28 \\
$\mathrm{Tl}_{2} \mathrm{Ba}_{2} \mathrm{CuO}_{\mathrm{y}}$ & 92 & $\mathrm{y}=6.2$ & $\mathrm{y}=6.0$ & 4 \\
$\mathrm{TlCa}_{2} \mathrm{Ba}_{2} \mathrm{Cu}_{3} \mathrm{O}_{\mathrm{y}}$ & 110 & $\mathrm{y}=9.0$ & $\mathrm{y}=9.0$ & 29 \\
$\mathrm{HgBa}_{2} \mathrm{Ca}_{2} \mathrm{Cu}_{3} \mathrm{O}_{\mathrm{y}}$ & 134 & $\mathrm{y}=8.5$ & $\mathrm{y}=8.4$ & 30 \\
\hline
\end{tabular}

From equation (2) we obtain the approximate result: $y=2.95$. This result is in good agreement with the experimental value $y=3.0$ reported in the literature ${ }^{31}$.

\section{Conclusion}

We believe that the simple model proposed in this paper in the case of $\mathrm{p}$ - Type oxide superconductors could also be extended to estimate the optimal doping of $\mathrm{n}$ - Type oxide superconductors. However, in the case of $\mathrm{n}$ - Type oxide superconductors, the reaction produced by oxygen doping is a reduction reaction instead of an oxidation reaction that occurs in $\mathrm{p}$ - Type oxide superconductors. Since we have not found in the literature any experimental determination of the oxygen content in the case of $\mathrm{n}$ - Type cuprate superconductors we shall not discuss this issue here. This question will be addressed in a future work.

We have proposed a simple model to estimate the relative concentrations of the ions involved to estimate the oxygen content for optimal doping of p-type oxide superconductors. It is important to know that the predictions based on this model are in good agreement with a number of reliable experimental results reported in the literature (Table 3). Thus we believe that our assumptions are helpful to the investigations of the microscopic mechanisms in oxide superconductors. We expect that this simple model will also be useful to encourage further experimental and theoretical researches in superconducting materials.

\section{References}

1. Bednorz JG, Müller KA. Possible high Tc superconductivity in the BaLa-Cu-O system. Zeitschrift fur Physik B, Condensed Matter 1986; 64(2): 189-193.

2. Yang J, Li ZC, Lu W, Yi W, Shen XL, Ren ZA, Che GC, Dong, XL, Sun, LL, Zhou F, Zhao ZX. Superconductivity at $53.5 \mathrm{~K}$ in GdFeAsO1- . Superconductor Science Technology 2008; 21; 082001: 1-3.

3. Cava RJ. Oxide superconductors. Journal American Ceramic Society 2000; 83(1): 5-28.

4. Rao CNR, Nagarajan R, Vijayaraghavan R. Synthesis of cuprate superconductors. Superconductor Science Technology 1993; 6(1): 1-22.

5. Schirber JE, Morosin B, Merrill RM, Hilava PF, Venturinie L, Kwak JF, Nigrey PJ, Baughman RJ, Ginley DS. Stoichiometry of bulk superconducting $\mathrm{La} 2 \mathrm{CuO} 4+\delta$ : A superconducting superoxide? Physica C 1988; 152(1): 121-123.
6. Wu MK, Ashburn JR, Torng CJ, Hor PH, Meng RL, Goa L, Huang ZJ, Wang YQ, Chu CW. Superconductivity at $93 \mathrm{~K}$ in a new mixed-phase $\mathrm{Y}-\mathrm{Ba}-\mathrm{Cu}-\mathrm{O}$ compound system at ambient pressure. Physical Review Letters 1987; 58(9): 908-910.

7. Remeika JP, Geballe TH, Matthias BT, Cooper AS, Hull GW, Kellye M. Superconductivity in hexagonal tungsten bronzes. Physics Letters A 1967; 24(11): 565-566.

8. Johnston DC, Prakash H, Zachariessen WH, Vishvanathan B. High temperature superconductivity in the Li-Ti-O ternary system. Materials Research Bulletin 1973; 8(7): 777-784.

9. Sleight AW, Gilson JL, Bierstedt PE. High-temperature superconductivity in the BaPb1-xBixO3 system. Solid State Communication 1975; 17: 27-28.

10. Mattheiss LF, Gyorgy EM, Johnson Jr DW. Superconductivity above $20 \mathrm{~K}$ in the Ba-K-Bi-O system. Physical Review B 1988; 37(7): 3745-3746.

11. Maeda H, Tanaka Y, Fukutomi M, Asano T. A new high-Tc oxide superconductor without a rare earth element. Japanese Journal of Applied Physics 1988; 27(2): L209-L210.

12. Burns G. High-Temperature Superconductivity - An Introduction. New York: Academic Press; 1992. p. 57.

13. Meng RL, Sun YY, Kulik J, Huang ZJ, Chen F, Xue YY, Chu CW. Superconductivity at 112-117 K in $\mathrm{HgBa} 2 \mathrm{CaCu} 2 \mathrm{O} 6+$. Physica C 1993; 214(3-4): 307-312.

14. Lee JD. Concise Inorganic Chemistry. London: Chapman \& Hall; 1991. chapters 7-28.

15. Ganguly P, Hegde MS. Evidence for double valence fluctuation in metallic oxides of lead. Physical Review B 1988; 37(10): 5107-5111.

16. Foltin J. Attractive interaction between electrons: An electron-pairing mechanism for superconductivity. Physical Review B 1988; 38(15): 10900-10902.

17. Callaway J, Kanhere DG, Misra PK. Polarization-induced pairing in high-temperature superconductivity. Physical Review B 1987; 36(13): 7141-7144.

18. Varma CM. Missing valence states, diamagnetic insulators, and superconductors. Physical Review Letters 1988; 61(23): 2713-2716.

19. Foltin J. Difference in high temperature superconductivity of two families of cuprate oxides. Physics Letters A 1989; 141(8-9): 427-428.

20. Wheatley JM, Hsu TC, Anderson PW. Interlayer pair hopping: Superconductivity from the resonating-valence-bond state. Physical Review B 1988; 37(10): 5897-5900.

21. Kamimura H. Cooperative bipolaron tunneling in high Tc copper oxide compounds and superconductivity. Japanese Journal of Applied Physics 1987; 26(5): L627-L630.

22. Alexandrov AS. Comment on "Experimental and theoretical constraints of bipolaronic superconductivity in high $T$ Materials: An impossibility". Physical Review Letters 1999 82(12): 2620-2620.

23. Jongh LJ. A comparative study of (bi)polaronic (super)conductivity in high- and low- Tc superconducting oxides. Physica C 1988; 152: 171-216.

24. Raveau B, Michel C, Hervieu M, Provost J. Crystal chemistry of perovskite superconductors. Physica C 1988; 153-155: 3-8.

25. Zhang H, Sato H. Universal relationship between $T_{c}$ and the hole content in $p$-type cuprate superconductors. Physical Review Letters 1993; 70(11): 1697-1699.

26. Kokkallaris S, Deligiannis K, Oussena M, Zhukov AA, Groot PAJ, Gagnon R, Taillefer L. Effect of oxygen stoichiometry on the out-ofplane anisotropy of $\mathrm{YBa}_{2} \mathrm{Cu}_{3} \mathrm{O}_{7}-\delta$ single crystals near optimal doping. Superconductor Science Technology 1999; 12(10): 690-693.

27. Hiroi Z, Takano M, Azuma M, Takeda Y. A new family of copper oxide superconductors $\mathrm{Sr}_{n}+{ }_{1} \mathrm{Cu}_{n} \mathrm{O}_{2 n}+1+\delta$ stabilized at high pressure. Nature 1993; 364(6435): 315-317.

28. Babaei M, Ross DK, Gorgiev PA, Khoshenevisan B, Yazdani A. Oxygen non-stoichiometry of bismuth-based $\mathrm{Bi}_{2} \mathrm{Sr}_{2} \mathrm{CaCu}_{2} \mathrm{O}_{8}+\delta(\mathrm{Bi}-2212)$ high temperature superconductor. Physica C 2003; 391(3): 289-297. 
29. Martin C, Maignan A, Provost J, Michel C, Hervieu M, Tournier R, Raveau B. Thalium cuprates: The critical temperature is mainly governed by the oxygen nonstoichiometry. Physica C 1990, 168(1-3): 8-22.

30. Hung KC, Lam C, Shao HM, Wang SD, Yao XX. Enhancement in flux pinning and irreversibility field by means of a short-time annealing technique for $\mathrm{HgBa}_{2} \mathrm{Ca}_{2} \mathrm{Cu}_{3} \mathrm{O}_{8.4}$ superconductor. Superconductor Science Technology 1997; 10(11): 836-842.

31. Cava RJ, Batlogg B, Krajewsky JJ, Farrow RL, Rupp Jr LW, White AE, Short K, Peck, WF, Kometani T. Superconductivity near $30 \mathrm{~K}$ without copper: the $\mathrm{Ba} \mathrm{K} \mathrm{BiO}$ perovskite. Nature 1988; 332(6167): 814-816. 